\title{
De relativiteit van een energielabel: EnergyClaim/Staat
}

\author{
$M r . R . M e i j e r^{*}$
}

\section{Inleiding}

Op basis van Europese regelgeving is het verplicht om voor gebouwen, waaronder woningen, een energielabel beschikbaar te hebben waaruit kan worden afgeleid hoe energie(on)zuinig een gebouw is. De doelstelling van deze regelgeving is het tegengaan van verdergaande $\mathrm{CO} 2$-uitstoot en daarmee het naleven van internationale milieuafspraken. Dat de regeling primair een milieudoelstelling nastreeft, wil niet zeggen dat hier geen vermogensrechtelijke aspecten aan kunnen kleven. Dat wordt geillustreerd door het in dit artikel te bespreken arrest van het Gerechtshof Den Haag, waarin de Stichting EnergyClaim (hierna: EnergyClaim) - in welke stichting ondernemingen die energieprestatiecertificaten afgeven zich hebben verenigd - de Nederlandse Staat (hierna: Staat) aanspreekt tot schadevergoeding wegens een onjuiste implementatie van het Unierecht. ${ }^{1}$ Deze schade zou bestaan uit de investeringen die de ondernemingen hebben gedaan - zoals het opleiden van gekwalificeerd personeel voor het kunnen afgeven van de energiecertificaten -, welke door het nalatig handelen van de Staat niet konden worden terugverdiend. Hierna wordt eerst de achtergrond van de zaak weergegeven gevolgd door het oordeel van het hof. Vervolgens zal ik enkele kanttekeningen plaatsen bij het arrest vanuit Unierechtelijk perspectief.

\section{Achtergrond}

\subsection{Nederlands beleid}

De huidige regelgeving omtrent het verplichte energielabel is gebaseerd op Europese wetgeving. Nederland liep hier echter al op vooruit. $\mathrm{Al}$ in 1995 introduceerde Nederland de zogeheten Energieprestatienorm, die energieprestatie-eisen stelde aan nieuwe gebouwen en woningen. In 2000 kwam daar het Energieprestatieadvies (EPA) bij. Het EPA maakte de energiezuinigheid van een woning inzichtelijk. Met de introductie van het EPA was er volgens de overheid behoefte aan een groot aantal EPA-adviseurs. Op dat moment was de aanwezigheid van een EPA nog vrijwillig. Wel werd het EPA door de overheid gestimuleerd door subsidies en fiscale regelingen. Ook werd door de Staat een convenant gesloten met onder meer woningcorporaties, waarin werd afgesproken dat voor ten minste $30 \%$ van de sociale huurwoningen een EPA zou wor-

Mr. R. Meijer is advocaat bij ZIPPRO MEIJER CITTEUR te Amsterdam.

1. Hof Den Haag 11 april 2017, ECLI:NL:GHDHA:2017:1251. den uitgebracht. Tegen de achtergrond van voornoemde ontwikkelingen hebben veel bedrijven investeringen gedaan in deze markt door onder meer het opleiden van gecertificeerde EPA-adviseurs. Daarbij zal ook een rol hebben gespeeld dat de Staat op meerdere momenten duidelijk heeft gemaakt dat - na invoering van de Europese regelingen - het zou gaan om een wettelijke verplichting om een EPA aan te bieden bij de verkoop of verhuur van woningen en gebouwen. ${ }^{2}$

\subsection{Omzetting van Europese regelgeving}

Op Europees niveau zijn er achtereenvolgens twee richtlijnen van belang. Allereerst was er Richtlijn 2002/91/EG betreffende de energieprestatie van gebouwen ('Energy Performance of Buildings Directive') (hierna: EPBD-richtlijn). Op basis van deze richtlijn diende er onder meer voor te worden gezorgd dat bij de bouw, verkoop of verhuur een energieprestatiecertificaat met een geldigheidsduur van tien jaar zou worden verstrekt. Deze certificering moest op een onafhankelijke wijze worden uitgevoerd door gekwalificeerde en/of erkende deskundigen. De omzettingstermijn van de EPBD-richtlijn verstreek op 4 januari 2006. Bij gebrek aan gekwalificeerde en/of erkende deskundigen hadden de lidstaten echter een extra termijn van drie jaar voor de naleving van delen van de richtlijn. Daarvan diende de Commissie wel in kennis te worden gesteld. In Nederland is de EPBD-richtlijn omgezet in het Besluit energieprestatie gebouwen (Beg) en de Regeling energieprestatie gebouwen (Reg). Kenmerkend voor het Beg en de Reg was dat deze regelingen aansloten bij het reeds bestaande (vrijwillige) kader voor energiecertificering en er geen handhavingssancties werden opgenomen. Dat werd door de Staat gemotiveerd met de opmerking in de nota van toelichting bij het Beg dat dit is gebeurd ter voorkoming van verdere verzwaring van de bestaande werklast van de overheid en rechterlijke macht. Ook zou hiervoor zijn gekozen om de administratieve lasten voor burgers en bedrijven in verband met het hebben van een energiecertificaat te beperken. Het Beg en de Reg zijn op 1 januari 2008 in werking getreden. Daarmee werd ook de ingebrekestelling van de Europese Commissie wegens de niettijdige omzetting van de richtlijn geseponeerd. Ook een twee-

2. Zoals ook het hierna nog te bespreken rapport van de Nationale ombudsman van 29 november 2010 (Rapportnummer 2010/334), heeft de Staat in het kader van een wervingscampagne om partijen uit te nodigen zich te begeven op de markt voor de energieprestatiecertificaten steeds gesproken over de verplichting tot het hebben van een energieprestatiecertificaat. Daarbij is niet expliciet gesproken over het uitblijven van handhaving van de verplichting tot het hebben van het energielabel. 
de inbreukprocedure is geseponeerd na wijzigingen van het Beg en de Reg.

De EPBD-richtlijn is met ingang van 1 februari 2012 ingetrokken en vervangen door Richtlijn 2010/31/EU (hierna: herziene EPBD-richtlijn). In vergelijking met de EPBD-richtlijn wordt er in de herziene EPBD-richtlijn in art. 27 nadrukkelijk een sanctioneringssysteem voorgeschreven dat uitgaat van doeltreffende, evenredige en afschrikkende sancties. Uiterlijk 9 januari 2013 moesten de lidstaten de Commissie laten weten welke sanctioneringsmaatregelen er waren getroffen in het nationale recht. Het oorspronkelijk ingediende wetsvoorstel ter implementatie van de herziene EPBD-richtlijn werd door de Tweede Kamer verworpen. Het wetsvoorstel zou leiden tot te hoge administratieve lasten en de sanctie via de 'notarisroute', waarbij zonder een energiecertificaat geen eigendomsoverdracht zou kunnen plaatsvinden, werd te zwaar bevonden. ${ }^{3}$ Op verzoek van de Tweede Kamer is er vervolgens gesproken over de mogelijkheden van een vereenvoudigd energielabel. Dit vereenvoudigde energielabel is uiteindelijk tot stand gekomen in het kader van de omzetting van de herziene EPBD-richtlijn. ${ }^{4}$ Het nieuwe Beg en de nieuwe Reg zijn met ingang van 1 januari 2015 in werking getreden. De omzetting van de herziene EPBD-richtlijn heeft geleid tot twee nieuwe inbreukprocedures. In eerste instantie betroffen de bezwaren van de Commissie dat Nederland geen melding had gemaakt van de maatregelen ter invoering van de richtlijn, wat later werd aangevuld met bezwaren over onder meer de sancties bij niet-naleving. Hierop heeft een wijziging van de Woningwet en het Beg plaatsgevonden. Dit heeft geleid tot intrekking van de ingebrekestelling, maar op 22 juli 2016 heeft de Commissie een nieuwe ingebrekestelling verzonden, die betrekking heeft op de (verkeerde) manier waarop Nederland uitvoering geeft aan de herziene EPBD-richtlijn. Deze procedure loopt nog.

\subsection{Huidig systeem van energiecertificering}

In het huidige systeem van energiecertificering wordt op basis van openbare gegevens (zoals het bouwjaar en kenmerken van de woning) een voorlopig energielabel vastgesteld. Woningeigenaren kunnen dit voorlopige energielabel aanvullen met behulp van een webtool met de belangrijkste energetische woningkenmerken met de bijbehorende bewijsstukken. Vervolgens wordt de juistheid van deze gegevens op afstand gecontroleerd door een erkend energielabeldeskundige. Deze deskundige kan eventueel ook aanvullende bewijsstukken opvragen. $\mathrm{Na}$ akkoord van de deskundige en toestemming van de woningeigenaar om een energielabel te registreren verstrekt de beheerder van de webtool, de Rijksdienst voor Ondernemend Nederland, het energielabel. De Inspectie Leefomgeving en Transport (ILT) houdt toezicht op de naleving van de verplichting tot het hebben van een energielabel en kan in geval van overtreding een last onder dwangsom en/of bestuurlijke boete opleggen.

3. De notaris zou de transportakte niet mogen verlijden zolang er geen energieprestatiecertificaat aanwezig was.

4. Zie voor de huidige regeling par. 2.3.

\subsection{Oordeel Ombudsman}

Naar aanleiding van klachten van het Comité EnergyClaim heeft de Nationale ombudsman (hierna: Ombudsman) onderzoek gedaan naar de gedragingen van de overheid met betrekking tot de EPA-adviseurs. In een rapport van 29 november 2010 heeft de Ombudsman de klachten gegrond verklaard. ${ }^{5}$ De Ombudsman oordeelde onder meer dat de overheid zich onbehoorlijk heeft gedragen door schending van het beginsel van rechtszekerheid en door onvoldoende rekening te houden met de belangen van kortweg de belanghebbenden aangesloten bij EnergyClaim bij de invoering van het energielabel en bij (de uitvoering van) het energielabelbeleid.

Ten aanzien van de schending van het rechtszekerheidsbeginsel oordeelde de Ombudsman:

'De participanten van verzoeker hebben redelijkerwijs op basis van de informatie die zij ontvingen, de overtuiging gekregen dat de verplichting van het hebben van een energielabel met zich meebrengt dat het energielabel niet vrijblijvend is en dat de Nederlandse overheid de burger houdt aan een dergelijke verplichting. De Nationale ombudsman is daarom van oordeel dat VROM/WWI verkeerde verwachtingen heeft gewekt bij de participanten van verzoeker.'

Volgens de Ombudsman was ook sprake van schending van het redelijkheidsvereiste. In dit kader oordeelde de Ombudsman onder meer:

'Het energielabel zoals dat destijds door de overheid is geïntroduceerd, is in de huidige tijd geen vitaal beleidsinstrument. Dit in tegenstelling tot het beeld dat bij de introductie ervan door de overheid is geschapen. De grote afstand tussen beide gegevens vraagt om een zeer grondige zelfreflectie van VROM/WWI. Dit enerzijds als het gaat om de geloofwaardigheid van de overheid, anderzijds als het gaat om de belangen van partijen in het maatschappelijk veld die ingespeeld hebben op het door de overheid gevormde beleid. De Nationale ombudsman is van oordeel dat VROM/WWI onvoldoende blijk heeft gegeven van die zelfreflectie en dat het onvoldoende recht heeft gedaan aan de ernst van de door VROM/WWI in het leven geroepen situatie. Dat blijkt al uit het feit dat VROM/WWI onvoldoende duidelijk heeft gemaakt dat de energielabelplicht niet gehandhaafd zou worden en dat VROM/WWI kennelijk heeft miskend dat op die wijze valse verwachtingen zijn geschapen waardoor de belangen van spelers in het maatschappelijk veld zijn geschaad. Tekenend is dat maatschappelijke partijen op grote schaal zijn gaan investeren in voorzieningen die noodzakelijk waren voor de invoering van het energielabel. De Nationale ombudsman is daarom van oordeel dat VROM/WWI onvoldoende rekening

5. Rapport Nationale ombudsman 29 november 2010, Rapportnummer $2010 / 334$. 
heeft gehouden met de belangen van de maatschappelijke partijen waar verzoeker voor optreedt.'

$\mathrm{Na}$ verschijning van het rapport van de Ombudsman hebben partijen getracht een minnelijke regeling te treffen. Dit is niet gelukt, waarna EnergyClaim een civiele procedure bij de Rechtbank Den Haag is begonnen.

\section{Arrest Gerechtshof Den Haag}

Net zoals de rechtbank wijst het hof de vorderingen van EnergyClaim af. De belangrijkste vorderingen - in het kader van deze bijdrage - betreffen de vordering tot nakoming van de verplichting tot juiste implementatie van de herziene EPBDrichtlijn en de vordering tot verklaring voor recht dat de Staat onrechtmatig heeft gehandeld jegens EnergyClaim.

\subsection{Rechtstreekse werking}

De vordering tot nakoming van een juiste implementatie was door de rechtbank afgewezen met als argument dat aan de bepalingen van de richtlijn geen rechtstreekse werking zou toekomen. ${ }^{6}$ Dat zou volgens de rechtbank ook gelden als de ruime relativiteitsbenadering van het Hof van Justitie van de Europese Unie (HvJ EU) als uitgangspunt wordt genomen. ${ }^{7}$ Het hof maakt met deze redenering terecht korte metten. De vereisten voor rechtstreekse werking zijn namelijk louter of de Uniebepalingen onvoorwaardelijk en voldoende duidelijk zijn en niet ook of de Uniebepaling ertoe strekt rechten toe te kennen aan particulieren (de relativiteitsvraag). Dat heeft de rechtbank miskend en op dit punt wordt terecht gegriefd. Dit leidt echter niet tot een andere uitkomst, aangezien het hof oordeelt dat niet voldaan is aan de vereisten voor rechtstreekse werking. De bepalingen waarop EnergyClaim zich beroept, zijn volgens het hof onvoldoende nauwkeurig om rechtstreekse werking te hebben. Daarvoor laten de bepalingen de lidstaten te veel keuzemogelijkheden.

\subsection{Unierechtelijke relativiteit}

Ook de verklaring voor recht van de onrechtmatigheid van het handelen van de Staat haalt het niet bij het hof. Met de rechtbank is het hof van oordeel dat niet voldaan is aan het relativiteitsvereiste. Daarbij beoordeelt het hof eerst of is voldaan aan de Unierechtelijke relativiteit. Daarbij neemt het hof tot uitgangspunt dat de EPBD-richtlijnen in de eerste plaats de bescherming van milieubelangen tot doel hebben. Dat blijkt uit de grondslag van de regeling (gebaseerd op de milieutitel van het Verdrag betreffende de Werking van de Europese Unie en de considerans van de EPBD-richtlijn waarin wordt gewezen op de noodzaak van een doelmatig, behoedzaam, rationeel en duurzaam energiegebruik). Aan de grondslag, considerans en inhoud van de EPBD-richtlijnen zijn volgens het hof geen aanwijzingen te ontlenen dat de richtlijnen ook zijn bedoeld om de belangen te dienen van de bedrijven waarvoor EnergyClaim opkomt. Het feit dat de richtlijnen voor-

6. Rb. Den Haag 14 mei 2014, ECLI:NL:RBDHA:2014:5878.

7. Zie r.o. 4.7. zien in een rol voor onafhankelijke, erkende energiecertificaatdeskundigen betreft slechts een neveneffect van de richtlijnen.

De verwijzing naar de arresten Danske Slagterier ${ }^{8}$ en Jutta Leth $^{9}$ door EnergyClaim maken dat niet anders. In die arresten was sprake van een zodanig nauwe samenhang tussen de doelstellingen van de geschonden norm - bevordering van de intracommunautaire handel (Danske Slagterier) en bescherming van het milieu en de kwaliteit van het bestaan (Jutta Leth) - en de belangen van eisers - invoer van vers vlees (Danske Slagterier) en behoud van de waarde van een woning (Jutta Leth) - dat het beschermingsbereik van de norm zich mede tot die belangen uitstrekte. Een dergelijke nauwe samenhang doet zich hier niet voor, aldus het hof. Het betreft bij de omzetderving van EPA-adviseurs veeleer indirecte economische gevolgen.

Ook vindt het hof van belang dat het relativiteitsvereiste grenzen stelt aan de groep benadeelden die vergoeding kunnen vorderen van de schade die zij lijden als gevolg van de overtreding van een norm. Dit veronderstelt dat die groep kan worden afgebakend. Naar het oordeel van het hof is dat in onderhavig geval niet mogelijk. EPA-adviseurs zijn immers niet de enige bedrijven die kunnen profiteren van maatregelen ter verbetering van de energieprestatie van gebouwen. Dat geldt bijvoorbeeld ook voor aannemers en installateurs. Indien EnergyClaim gevolgd zou worden in de redenering dat aan het relativiteitsvereiste is voldaan, zou datzelfde gelden voor alle andere bedrijven die nadelige economische gevolgen ondervinden van de niet-tijdige of onjuiste implementatie. Daarmee zou het relativiteitsvereiste zijn betekenis verliezen, aldus het hof. ${ }^{10}$

\subsection{Nederlands relativiteitsvereiste}

Vervolgens toetst het hof of is voldaan aan het Nederlandse relativiteitsvereiste. De Unierechtelijke aansprakelijkheidscriteria zijn immers minimumvereisten en sluiten niet uit dat naar Nederlands recht wel aansprakelijkheid kan worden aangenomen. Er is echter ook niet voldaan aan het Nederlandse relativiteitsvereiste. Daarbij verwijst het hof allereerst wederom naar het doel en de strekking van de EPBD-richtlijnen, die uitgaan van een milieudoelstelling. Het hof volgt EnergyClaim ook niet in haar betoog dat de rechtbank ten onrechte niet is uitgegaan van de ruimere toepassing van het relativiteitsvereiste uit de arresten Barneveld/Gasunie, ${ }^{11}$ Hangmat, ${ }^{12}$ Fabricom II $^{13}$ en Imagine, ${ }^{14}$ maar de terughoudende lijn van de arresten Duwbak Linda ${ }^{15}$ en Iraanse vluchteling ${ }^{16}$ heeft gevolgd. Het hof verwerpt dit verwijt door te wijzen op de verschillen tussen de situatie in de aangehaalde arresten en de onderhavige

\footnotetext{
8. HvJ EU 24 maart 2009, C-445/06, ECLI:EU:C:2009:178.

9. HvJ EU 14 maart 2013, C-420/11, ECLI:EU:C:2013:166

10. R.o. 30.

11. HR 13 juli 2007, ECLI:NL:HR:2007:AZ1598.

12. HR 8 oktober 2010, ECLI:NL:HR:2010:BM6095.

13. HR 31 oktober 2014, ECLI:NL:HR:2014:3073.

14. HR 29 januari 2016, ECLI:NL:HR:2016:162.

15. HR 7 mei 2004, ECLI:NL:HR:2004:AO6012.

16. HR 13 april 2007, ECLI:NL:HR:2007:AZ8751.
} 
zaak. Zo is hier geen sprake van een nauwe samenhang tussen het belang dat wordt nagestreefd met de EPBD-richtlijnen en de belangen van EnergyClaim. Evenmin zijn de certificeringsdeskundigen te beschouwen als de materieel begunstigden van de richtlijnen en kan reeds uit de tekst van de EPBD-richtlijn worden vastgesteld dat hiermee niet wordt beoogd de belangen van certificeringsdeskundigen te dienen, aldus het hof.

\subsection{Correctie Langemeijer}

Het beroep op de correctie Langemeijer - waarbij de omstandigheid dat een wettelijke norm is geschonden die niet strekt tot bescherming tegen de schade zoals die is geleden, kan bijdragen aan het oordeel dat een ongeschreven zorgvuldigheidsnorm is geschonden jegens de benadeelde partij - slaagt evenmin. Het hof merkt op dat EnergyClaim in dit verband niet kan volstaan met de stelling dat een zorgvuldigheidsnorm is geschonden door kortweg de EPBD-richtlijn niet tijdig of niet juist om te zetten. Afgezien van deze mogelijke schending van de wettelijke verplichting tot omzetting van de richtlijnen zal sprake moeten zijn van schending van een zorgvuldigheidsnorm. Daarvan is volgens het hof geen sprake. De Staat heeft een ruime mate van vrijheid om wet- en regelgeving en beleid te wijzigen, ook als daardoor eerdere verwachtingen teniet worden gedaan. Dat valt onder het normale ondernemingsrisico. ${ }^{17}$ Verder zijn er geen concrete toezeggingen gedaan waardoor een gerechtvaardigd vertrouwen is gewekt. De uitlatingen waarop EnergyClaim zich in dit verband heeft beroepen, bevatten naar het oordeel van het hof geen dermate concrete toezeggingen dat daarmee bij de EPA-adviseurs de gerechtvaardigde verwachting kan zijn gewekt dat zij een bepaalde omzet zouden kunnen behalen met energieprestatiecertificering. Het enige document waarin over een concrete omzetverwachting werd gesproken, betrof een rapport dat dateerde van vóór de inwerkingtreding van de EPBD-richtlijnen. Slotsom is dat niet duidelijk is gemaakt in welk opzicht sprake is van een schending van het zorgvuldigheidsbeginsel, naast de mogelijke schending van de wettelijke verplichting tot juiste omzetting van de EPBD-richtlijnen.

\subsection{Invloed rapport Ombudsman}

Ook het kritische rapport van de Ombudsman, dat schending van het rechtszekerheidsbeginsel en redelijkheidsvereiste concludeerde, leidt niet tot een ander oordeel. Het hof stelt voorop dat de rechter niet is gebonden aan het oordeel van de Ombudsman en herinnert eraan dat de Ombudsman ook niet dezelfde normen hanteert als de rechter. Volgens het hof kan op basis van de constateringen van de Ombudsman geen schending van het vertrouwens- of zorgvuldigheidsbeginsel worden aangenomen. Er bestaat geen verplichting voor de Staat om bedrijven die gevolgen ondervinden van wetgeving steeds op voorhand te informeren over de inhoud daarvan. Ook mag volgens het hof worden aangenomen dat de EPAadviseurs bekend waren met de inhoud van de EPBD-richtlijn waarin geen sanctieverplichting was opgenomen. De vereen-

17. R.o. 41. voudiging van het energielabel kan ook niet worden gezien als een inbreuk op het vertrouwens- of zorgvuldigheidsbeginsel. Terugkomen van een eerdere verdergaande variant van het energielabel waarover aan de markt mededelingen zijn gedaan, valt binnen de vrijheid van de Staat om wet- en regelgeving en beleid te wijzigen. Niet-uitgekomen verwachtingen van de EPA-adviseurs behoren tot het normale ondernemersrisico, aldus nog steeds het hof.

\section{Commentaar}

De manier waarop de wetgever is omgegaan met het energiecertificaatdossier verdient bepaald niet de schoonheidsprijs. Dat is toch in ieder geval de conclusie die zich opdringt na vier inbreukprocedures door de Europese Commissie - weliswaar tot op heden (er loopt nog een inbreukprocedure) zonder veroordeling - en een zeer kritisch rapport van de Ombudsman. Dat wil echter niet zeggen dat hiermee dus ook onrechtmatig is gehandeld jegens partijen die zijn benadeeld. Voor de EPAadviseurs strandt de zaak op het relativiteitsvereiste. Dat is een bekend struikelblok in procedures tegen de overheid. Het arrest van het hof is uitvoerig in zijn motivering waarom niet is voldaan aan het relativiteitsvereiste. Desondanks zijn er wel enkele kanttekeningen te plaatsen bij dit oordeel. Daarbij concentreer ik me met name op de Unierechtelijke aspecten van de zaak.

\subsection{Unierechtelijke relativiteit versus Nederlandse relativiteit}

Het hof toetst afzonderlijk aan het Unierechtelijke en Nederlandse relativiteitsvereiste. Op basis van het Unierecht zijn de vereisten voor lidstaataansprakelijkheid dat (1) de geschonden norm rechten toekent aan particulieren, (2) sprake is van een voldoende gekwalificeerde schending, en (3) een rechtstreeks causaal verband bestaat tussen de schending en de geleden schade. ${ }^{18}$

Het vereiste dat de geschonden norm rechten moet toekennen aan particulieren, is de Unierechtelijke pendant van het relativiteitsvereiste. In het algemeen kan worden gezegd dat het $\mathrm{HvJ}$ EU een ruime benadering hanteert van het Unierechtelijke relativiteitsvereiste. ${ }^{19}$ Het is voldoende dat de normen beogen aan particulieren een zekere bescherming te bieden. Het is niet nodig dat één of meer bepalingen uit de Unieregeling daarop zijn gericht. Daarbij maakt het niet uit of de Unieregeling als geheel ook andere doelen nastreeft. ${ }^{20}$ Ook is niet nodig dat er expliciet wordt gewezen op rechten van particulieren. Een norm gegeven ter bescherming van een algemeen belang kan

18. HvJ EG 19 november 1991, C-6/90 en C-9/90, Jur. 1991, p. I-5357 (Francovich en Bonifaci) en HvJ EG 5 maart 1996, C-46/93 en C-48/93, Jur. 1996, p. I-1029 (Brasserie du Pêcheur en Factortame).

19. Zie bijv. C.H. Sieburgh, EU Law and Non-Contractual Liability, in: A.S Hartkamp e.a. (red.), The Influence of EU Law on National Private Law, Deventer: Kluwer 2014, p. 477 e.v.

20. HvJ EG 8 oktober 1996, C-178/94, C-179/94, C-188/94, C-189/94 en C-190/94, Jur. 1996, p. I-4845 (Dillenkofer). 
daarnaast ook de strekking hebben belangen van particulieren te beschermen. ${ }^{21}$

Het vereiste dat de geschonden norm rechten toekent aan particulieren vormt dus een betrekkelijk laagdrempelige voorwaarde voor het aannemen van de Unierechtelijke lidstaataansprakelijkheid. Even leek het arrest Peter Paul hierin verandering te brengen. ${ }^{22}$ Latere rechtspraak maakt echter duidelijk dat de ruimhartige relativiteitstoepassing nog steeds het uitgangspunt is en dat Peter Paul kan worden gezien als een uitzondering op deze regel. Arresten waarin de ruime benadering is te herkennen, zijn onder meer de hierboven reeds aangehaalde arresten Danske Slagterier en Jutta Leth (waarover hierna meer).

In het licht van de in beginsel soepele benadering van de Unierechtelijke relativiteit ('rechten toekennen aan particulieren') kan het zomaar zijn dat de Nederlandse relativiteitsbenadering strenger uitpakt. Het Gerechtshof Den Haag onderkent dat ook, waar het - zij het voorzichtig - stelt dat het aansprakelijkheidsvereiste dat de geschonden Unienorm rechten moet toekennen aan particulieren vergelijkbaar 'maar mogelijk niet geheel gelijk [is] aan' het relativiteitsvereiste van art. 6:163 van het Burgerlijk Wetboek (BW). ${ }^{23}$ Het casuïstische karakter van zowel de Nederlandse als de Europese relativiteitsjurisprudentie maakt het lastig om in algemene zin uitspraken te doen wanneer beide benaderingen uit elkaar lopen. Dat maakt de

21. HvJ EG 14 juli 1967, C-5/66, 7/66, 13/66 en 24/66, Jur. 1967, p. 306 (Kampffmeyer); concl. A-G Alber 15 mei 2003, C-92/02 P, Jur. 2003, p. I-10497, nr. 118 (Biret).

22. HvJ EG 12 oktober 2004, C-222/02, Jur. 2004, p. I-9425 (Peter Paul). In deze zaak ging het om de schending van verschillende bankenrichtlijnen, waaronder de Depositogarantierichtlijn. In antwoord op prejudiciële vragen van het Duitse Bundesgerichtshof in een procedure over aansprakelijkheid voor schade veroorzaakt door gebrekkig toezicht op kredietinstellingen oordeelde het $\mathrm{HvJ} \mathrm{EU}$ dat de betrokken richtlijnen er niet toe strekken om rechten toe te kennen aan particulieren. Dit was enigszins verrassend, aangezien de geschonden richtlijnen naast andere doelstellingen, ook het oog hadden op de bescherming van de deposanten. Toch oordeelde het HvJ EU dat uit het feit dat de bescherming van de deposanten wordt genoemd als een van de doelstellingen, niet noodzakelijkerwijs voortvloeit dat de richtlijnen rechten beogen te creëren ten gunste van de deposanten indien hun deposito's door gebrekkig toezicht van de bevoegde nationale autoriteiten niet beschikbaar zijn geworden. Het $\mathrm{HvJ}$ EU hanteerde hier dus een strikte benadering. Daarbij woog het HvJ EU mee dat de harmonisatie van de richtlijnen beperkt is tot hetgeen wezenlijk, noodzakelijk en voldoende is om te komen tot de wederzijdse erkenning van de vergunningen en van de stelsels van bedrijfseconomisch toezicht. De coördinatie van de nationale voorschriften inzake de aansprakelijkheid van de nationale autoriteiten jegens de deposanten in geval van gebrekkig toezicht lijkt volgens het HvJ EU niet noodzakelijk om de met de richtlijn beoogde resultaten te bereiken. Het HvJ EU verwijst in zijn arrest ook nadrukkelijk naar de omstandigheid dat verschillende lidstaten de mogelijkheid van aansprakelijkheid van financieel toezichthouders hebben uitgesloten of beperkt. Rechtspolitieke overwegingen lijken dus ook een belangrijke rol te hebben gespeeld bij het oordeel. Zie ook C.C. van Dam, Aansprakelijkheid voor falend toezicht in tijden van financiële cholera - over coma-bankieren, vuvuzela-juristerij en De Nederlandsche bank, NTBR 2010, p. 232 en R. Meijer, Rechtspolitieke overwegingen in de Unie- en lidstaatsaansprakelijkheid, in: T. Barkhuysen e.a. (red.), Coulant compenseren? Over overheidsaansprakelijkheid en rechtspolitiek, Deventer: Kluwer 2012, p. 659-672.

23. R.o. 26. toch al ingewikkelde zoektocht naar het beschermingsbereik van de geschonden norm extra gecompliceerd. ${ }^{24}$

Hierbij speelt ook een rol dat er een rechtspolitieke dimensie zit aan het relativiteitsvereiste. Het is immers zelden het geval dat de geschonden norm of de toelichting van de wetgever daarbij expliciet aangeeft wat het beoogde beschermingsbereik is van de norm. De rechter zal dat dus zelf moeten bepalen aan de hand van de wel beschikbare informatie. Hoe ruimer het beschermingsbereik wordt vastgesteld, hoe meer benadeelden recht hebben op schadevergoeding bij schending van de norm. Zeker in procedures tegen de overheid speelt dit een belangrijke rol, omdat een ruime vaststelling dus kan resulteren in een veelheid aan schadeclaims. Het relativiteitsvereiste is dan het instrument om deze potentiële aansprakelijkheid in te dammen.

Ook in onderhavig arrest wijst het hof erop dat het relativiteitsvereiste grenzen stelt aan de groep benadeelden die vergoeding kunnen vorderen van schade die zij lijden als gevolg van de overtreding van een norm, hetgeen veronderstelt dat die groep kan worden afgebakend. ${ }^{25}$ Daarin schuilt een probleem, aangezien deze duidelijke afbakening niet mogelijk is volgens het hof. Dat zou ertoe leiden dat naast de EPA-adviseurs eigenlijk elk bedrijf dat nadelige economische consequenties ondervindt, zijn schade zou kunnen verhalen op de Staat. Daarmee zou volgens het hof het relativiteitsvereiste zijn betekenis verliezen.

Dit floodgate-argument is niet nieuw. Het is naar mijn mening echter wel opvallend dat dit argument wordt gebruikt in de context van de toetsing aan het Unierechtelijke relativiteitsvereiste. Want hoewel ook het Unierechtelijke vereiste van rechten toekennen aan particulieren onmiskenbaar een beperking vormt van de aansprakelijkheid, wil dat niet zeggen dat het floodgate-argument onverkort van toepassing is in de context van de Unierechtelijke lidstaataansprakelijkheid. Dit raakt ook de rechtspolitieke dimensie die zojuist werd aangestipt. De rechtspolitieke afweging kan bezien vanuit het Unierecht immers heel goed afwijken van de afweging bezien vanuit het Nederlandse recht. Daarbij moet in het oog worden gehouden dat de Unierechtelijke lidstaataansprakelijkheid ook een instrument is voor de goede doorwerking van het Unierecht in de lidstaten. Deze dimensie kan meespelen bij de (rechtspolitieke) afweging of de schending van een Unienorm moet kunnen resulteren in lidstaataansprakelijkheid. Ik meen dan ook dat het hof het Unierechtelijke relativiteitsvereiste op dit punt te veel heeft bekeken vanuit het zuiver Nederlandse perspectief.

24. Zie over het relativiteitsvereiste bijv. de proefschriften van P.W. den Hollander, De relativiteit van wettelijke normen (diss. Leiden), Den Haag: Boom juridisch 2016 en - toegespitst op overheidsaansprakelijkheid L. Di Bella, De toepassing van de vereisten van causaliteit, relativiteit en toerekening bij de onrechtmatige overheidsdaad (diss. Leiden), Deventer: Kluwer 2014.

25. R.o. 29. 


\subsection{Indirecte economische gevolgen?}

De verwijzing door EnergyClaim naar de arresten Danske Slagterier en Jutta Leth ter onderbouwing van haar stelling dat voldaan is aan het relativiteitsvereiste, slaagt niet bij het hof. Het gaat hier volgens het hof om indirecte economische gevolgen, die op één lijn kunnen worden gesteld met de concurrentienadelen genoemd door het $\mathrm{HvJ}$ EU in het arrest Jutta Leth'.

Het is wat mij betreft niet volstrekt evident dat de nadelige gevolgen voor de EPA-adviseurs een-op-een kunnen worden vergeleken met de concurrentienadelen zoals genoemd in het arrest Jutta Leth. Dit arrest betrof de vordering tot schadevergoeding tegen de Oostenrijkse Staat ingesteld door Jutta Leth. De vordering bestond uit (onder meer) de waardevermindering van haar woning door het niet tijdig en onvolledig omzetten van de Richtlijnen 85/337, 97/11 en 2003/35 (hierna samen: de MEB-richtlijn) en het niet uitvoeren van milieueffectbeoordelingen bij het afgeven van de vergunningen voor het uitbreiden van een in de directe nabijheid van haar woning gelegen luchthaven. Op basis van de MEB-richtlijn hadden de directe en indirecte effecten van het project - in dit geval bestaande uit de uitbreiding van de luchthaven - moeten worden beoordeeld op een aantal factoren, waaronder de effecten op materiële goederen. Hier oordeelde het HvJ EU dat de milieubeoordeling niet de vermogenswaarde van materiële goederen omvat. Het doel van de MEB-richtlijn is de bescherming van het milieu en het bestaan van kwaliteit te verwezenlijken. Dit betekent volgens het HvJ EU echter niet noodzakelijk dat de MEB-richtlijn particulieren geen recht verleent op vergoeding van vermogensschade door vermindering van de waarde van hun materiële goederen. De voorkoming van vermogensschade valt namelijk wel onder de beschermingsdoelstelling van de MEB-richtlijn indien de schade het rechtstreekse economische gevolg van de milieueffecten van een project is. Deze schade die het rechtstreekse gevolg is van dergelijke milieueffecten moet volgens het HvJ EU worden onderscheiden van de schade die niet rechtstreeks voortspruit uit milieueffecten en die niet onder de beschermingsdoelstelling valt, zoals bepaalde concurrentienadelen.

De vraag is dus of de schade zoals die is geleden door de EPAadviseurs moet worden beschouwd als schade die het rechtstreekse economische gevolg is van de maatregelen die ertoe strekken het energieverbruik terug te dringen door de energieprestaties van gebouwen te verbeteren. De EPBD-richtlijnen schrijven voor dat de energieprestatiecertificering dient te gebeuren door onafhankelijke deskundigen (in Nederland: de EPA-adviseurs). Als deze EPA-adviseurs, die een cruciaal onderdeel vormen van de richtlijn en noodzakelijk zijn voor het kunnen verwezenlijken van de doelstellingen van de richtlijn, nu schade lijden door een onjuiste implementatie van de richtlijn, is dat dan inderdaad indirecte schade die gelijk kan worden gesteld aan concurrentienadelen die het HvJ EU als voorbeeld noemt in het arrest Jutta Leth? Ik ben daar nog niet zeker van. Juist omdat de energieprestatiecertificaatdeskundi- gen expliciet worden benoemd in de richtlijn en een onlosmakelijk onderdeel vormen bij de uitvoering van de richtlijn zou een ander oordeel - namelijk dat de EPA-adviseurs wel onder het beschermingsbereik vallen - niet ondenkbaar zijn. EnergyClaim is in cassatie gegaan van het arrest van het hof. Daar zal dit ongetwijfeld onderwerp van discussie zijn, waarbij waarschijnlijk ook de vraag zal rijzen in hoeverre de Hoge Raad dit kan afdoen zonder prejudiciële vragen te stellen aan het $\mathrm{HvJ}$ EU.

\section{Afronding}

De EPBD-richtlijnen beogen dat gebouwen energiezuiniger worden door een energieprestatiecertificaat verplicht te stellen. Het implementatietraject van de richtlijnen is niet zonder rimpelingen verlopen. Er loopt nog steeds een inbreukprocedure tegen Nederland. De vordering van de door EnergyClaim vertegenwoordigde benadeelde EPA-adviseurs slaagt echter niet, omdat de EPA-richtlijnen volgens het hof niet beogen te beschermen tegen de door hen geleden schade. In ieder geval vanuit Unierechtelijk perspectief valt hier het een en ander op af te dingen. Het is naar mijn mening minder evident dat niet is voldaan aan het Unierechtelijke relativiteitsvereiste dan nu in het arrest naar voren komt. Dat heeft ermee te maken dat de Unierechtelijke lidstaataansprakelijkheid een instrument is om te waarborgen dat het Unierecht goed doorwerkt in het nationale recht. ${ }^{26}$ Dit element maakt dat het Unierecht soms tot een andere relativiteitsafweging kan komen dan het Nederlandse recht. In combinatie met de ruimhartige benadering bij de toepassing van het Unierechtelijke relativiteitsvereiste kan er daarom worden getwijfeld aan het oordeel van het hof dat de schade van de EPA-adviseurs niet onder het Unierechtelijke beschermingsbereik valt.

26. Lees: goed wordt omgezet (voor zover nodig) en toegepast, en effectief wordt gehandhaafd. 